\title{
An unusual cause of recurrent seizures
}

\section{H Gunasekara ${ }^{1}$, M Wijeratne ${ }^{2}$ and P Ambawatta ${ }^{3}$}

\section{Introduction}

Glioependymal cysts are congenital epithelial cysts of the neuraxis. They have a characteristic inner lining, which consists of glial and ependymal cells. They are developmental anomalies arising from inappropriate displacement and heterotopia (ectopic gray matter) of ventricular epithelium during neuronal migration [1].

\section{Case report}

A 14-year old boy had a history of generalised tonic- clonic seizures from the age of 6 years. He was free of seizures until 6 months ago when seizures recurred, associated with intermittent headache. Neurological examination was normal. The electroencephalograph showed left-sided focal sharp wave activity. Cranial CT scan revealed a well-defined non-enhancing cystic mass, eroding the adjacent skull (figure 1). Radiological diagnosis was a 'pilocytic astrocytoma'.

Craniotomy and complete excision of the cystic mass was performed. Histology of the cyst wall showed an

${ }^{1}$ Neurologist, ${ }^{2}$ Neurosurgeon, and ${ }^{3}$ Pathologist, Sri Jayewardenepura General Hospital, Nugegoda, Sri Lanka. Correspondence: HG, e-mail: <hemalhg@yahoo.co.uk>. Received 13 September 2007 and revised version accepted 11 January 2008. Conflicts of interest: none declared. 


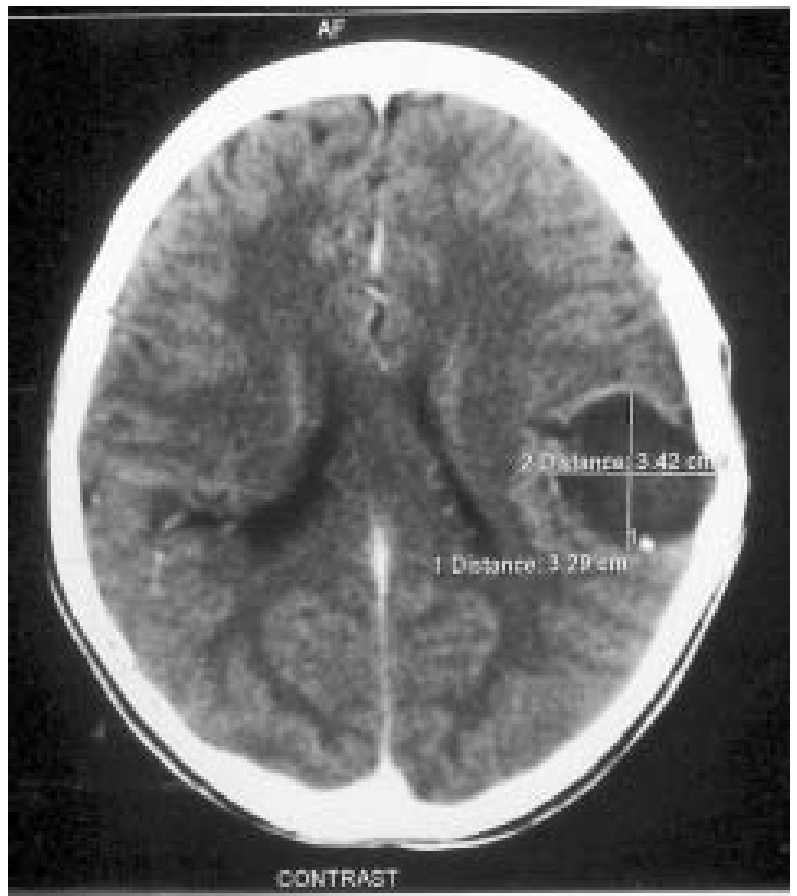

Figure 1. Contrast-enhanced computed tomography image of the "cystic mass" in the left parietal lobe, eroding into the skull bone.

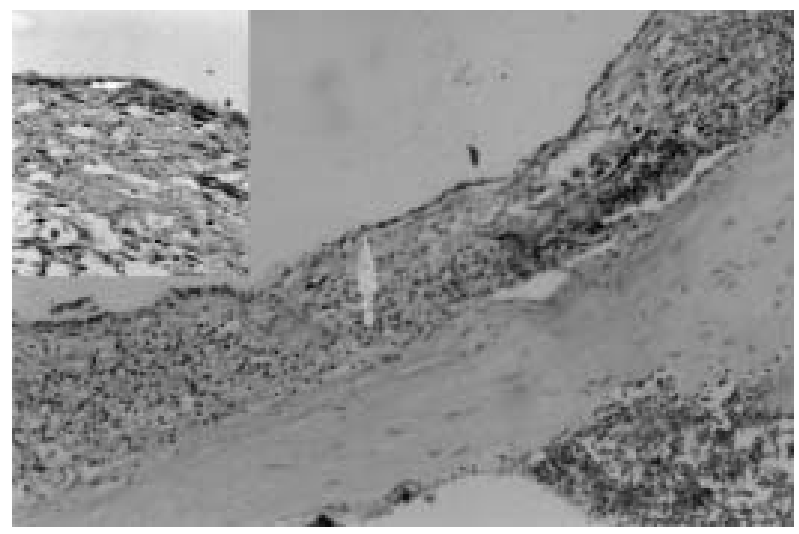

Figure 2. Photomicrograph of the cyst wall showing low-cuboidal epithelial cells in the luminal surface (arrow), and fibrous tissue and glial cells in the outer layer (H\&E stain $x$ 400). Inset - immunostaining of the inner wall showing dark glia-like cells (arrow) stained positively for GFAP. inner layer of flattened, low cuboidal epithelium and an outer layer of fibrous connective tissue with dark glia-like cells staining positively for glial fibrillary acidic protein (GFAP), confirming the diagnosis of a glioependymal cyst (figure 2).

\section{Discussion}

Glioependymal cysts may remain silent for years or expand, causing symptoms by compression of adjacent brain or expanding the overlying skull. They are commonly situated in the paraventricular white matter of the frontal and parietal lobes [2].

Presentation is usually prenatal or neonatal with hydrocephalus, agenesis of corpus callosum and seizures. Glioependymal cysts appear hypodense on CT and do not enhance. On MRI, they appear isointense with CSF on T1-weighted images and show iso- or mild hyperintensity on T2-weighted images [3].

Glioependymal cyst has to be differentiated from simple 'glial' cyst (devoid of lining epithelium), arachnoid cyst (loculated accumulations of CSF enclosed by fibroconnective tissue derived from leptomeninges) and pilocytic astrocytoma (a non-infiltrative focal astrocytoma of childhood) [3]. Immunohistochemical staining with glial fibrillary acidic protein (GFAP) of the inner epithelium is positive in glioependymal cysts and negative in arachnoid cysts. Complete removal of the cyst is the preferred method of treatment as subtotal resection may lead to recurrence.

\section{References}

1. Friede RL, Yasargil MG. Supratentorial intracerebral epithelial (ependymal) cysts: review, case reports and fine structure. Journal of Neurology, Neurosurgery and Psychiatry 1977; 40: 127-37.

2. Rosenblum MK, Bilbao JM, Ang LC. Cysts of the central neuraxis. In: Rosal J eds. Ackerman's Surgical Pathology (8th ed.), New York: Mosby; 1989: 2235.

3. Ismail A, Tampieri D, Melanson D, Pokrupa R, Villemure JG, Bertrand G. Glioependymal cysts: CT and MR findings. Journal of Computer Assisted Tomography 1992; 16: $860-4$ 